\title{
Moderate activation of IKK2-NF-kB in unstressed adult mouse liver induces cytoprotective genes and lipogenesis without apparent signs of inflammation or fibrosis
}

\author{
Hong Lu*, Xiaohong Lei and Qinghao Zhang
}

\begin{abstract}
Background: The NF-kB signaling, regulated by IKK1-p52/RelB and IKK2-p65, is activated by various stresses to protect or damage the liver, in context-specific manners. Two previous studies of liver-specific expression of constitutive active IKK2 (IKK2Ca) showed that strong activation of IKK2-NF-kB in mouse livers caused inflammation, insulin resistance, and/ or fibrosis. The purpose of this study was to understand how moderate activation of IKK2-NF-kB in adult mouse livers alters hepatic gene expression and pathophysiology.
\end{abstract}

Method: We generated mice with adult hepatocyte-specific activation of Ikk2 (Liv-lkk2ca) using Alb-cre mice and Ikk2ca Rosa26 knockin mice in which a moderate expression of Ikk2ca transgene was driven by the endogenous Rosa26 promoter.

Results: Surprisingly, compared to wild-type mice, adult male Liv-lkk2ca mice had higher hepatic mRNA expression of Ikk2 and classical NF-kB targets (e.g. Lcn2 and A20), as well as IKK1, NIK, and RelB, but no changes in markers of inflammation or fibrosis. Blood levels of IL-6 and MCP-1 remained unchanged, and histology analysis showed a lack of injury or infiltration of inflammatory cells in livers of Liv-lkk2ca mice. Moreover, Liv-lkk2ca mice had lower mRNA expression of prooxidative enzymes Cyp2e1 and Cyp4a14, higher expression of antioxidative enzymes Sod2, Gpx1, and Nqo1, without changes in key enzymes for fatty acid oxidation, glucose utilization, or gluconeogenesis. In parallel, Liv-lkk2ca mice and wild-type mice had similar levels of hepatic reduced glutathione, endogenous reactive oxygen species, and lipid peroxidation. Additionally, Liv-lkk2ca mice had higher Cyp3a11 without down-regulation of most drug processing genes. Regarding nuclear proteins of NF-kB subunits, Liv-lkk2ca mice had moderately higher p65 and p50 but much higher RelB. Results of ChIP-qPCR showed that the binding of p50 to multiple NF-kB-target genes was markedly increased in Liv-lkk2ca mice. Additionally, Liv-lkk2ca mice had moderate increase in triglycerides in liver, which was associated with higher lipogenic factors Ppary, Lxr, Fasn, Scd1, and CD36.

Conclusion: In summary, moderate activation of IKK2-NF-kB in unstressed adult mouse hepatocytes produces a cytoprotective gene expression profile and induces lipogenesis without apparent signs of inflammation or fibrosis, likely due to strong activation of the anti-inflammatory IKK1-RelB alternative NF-kB pathway as well as the Lxr.

Keywords: IKK2, IKK1, NF-kB, RelB, Lxr, Liver, Mice, Lipogenesis, Inflammation, Fibrosis

\footnotetext{
* Correspondence: luh@upstate.edu

Department of Pharmacology, SUNY Upstate Medical University, $750 \mathrm{E}$

Adams ST, Syracuse, NY 13210, USA
}

\section{Biomed Central}

(c) 2015 Lu et al. This is an Open Access article distributed under the terms of the Creative Commons Attribution License (http://creativecommons.org/licenses/by/4.0), which permits unrestricted use, distribution, and reproduction in any medium, provided the original work is properly credited. The Creative Commons Public Domain Dedication waiver (http:// creativecommons.org/publicdomain/zero/1.0/) applies to the data made available in this article, unless otherwise stated. 


\section{Background}

Oxidative stress and inflammation are highly prevalent in major liver diseases, such as viral hepatitis, alcoholic and non-alcoholic steatohepatitis, liver cirrhosis, and liver cancer. Being a master regulator of inflammation and cytoprotection [1], NF-kB signaling is tightly regulated by the inhibitor of nuclear factor-kappaB (IkappaB) kinase 1 (IKK1) and IKK2. In unstimulated cells, NF-kB dimers p 65 and p50 are sequestered in cytosol by inhibitor of $\mathrm{kB}$ $\alpha(\mathrm{IkB} \alpha)$. The IKK complex has two catalytic subunits, IKK2 and IKK1, which activate NF-kB via the classical and alternative pathways, respectively [2]. In classical pathway, upon activation by stimuli such as tumor necrosis factor $\alpha$ (TNF $\alpha)$, IKK2 is phosphorylated, which in turn phosphorylates $\mathrm{IkB} \alpha$. This leads to degradation of $\mathrm{IkB} \alpha$, nuclear translocation of p65/p50, and induction of NF$\mathrm{kB}$-dependent genes, including inflammatory genes TNF $\alpha$ and interleukin-6 (IL-6). The alternative NF-kB pathway is activated by distinct ligands via phosphorylation of IKK1, leading to processing of p100 and release of p52 and RelB into nucleus, resulting in induction of unique subsets of NF-kB-dependent genes by RelB/p52 and RelB/p50 dimers $[1,2]$.

NF- $\mathrm{kB}$ is a survival factor for hepatocytes [3, 4], and $\mathrm{NF}-\mathrm{kB}$ is activated by various stresses to protect or damage the liver, in context-specific manners [3]. Thus, to improve the efficacy and decrease the hepatotoxicity of drug treatment, it is of paramount importance to understand the context-specific roles of IKK2-NF-kB signaling in liver pathophysiology, particularly in hepatocytes. Intriguingly, activation of IKK2-NF-kB causes contextspecific effects on liver pathophysiology. Activation of IKK2-NF-kB in hepatocytes is critical in protecting hepatocytes from TNFo- and bile-acid-induced cell death $[3,4]$. In contrast, superactivation of IKK2 in neonatal liver through Tet-Off hepatocyte-specific transgenic expression of constitutively active IKK2 (IKK2ca) markedly activates p65 and induces proinflammatory genes, chronic inflammation, and liver fibrosis in adult mice [5]. Conversely, when hepatocyte-specific expression of Ikk2ca was driven by a strong albumin promoter, adult Ikk2ca transgenic mice have normal liver histology (no fibrosis) but induction of proinflammatory cytokines IL-1 $\beta$ and IL6 as well as 2 rate-limiting enzymes for gluconeogenesis, namely phospho-enolpyruvate carboxykinase (Pepck) and glucose-6-phosphatase (G6pc) [6]. In these Ikk2ca transgenic mice, hepatocytes is the primary source of IL-6 production, which plays a key role in insulin resistance [6]. Currently, the mechanism of context-specific roles of IKK2 in hepatic NF-kB activation, gene expression, and pathophysiology remains unknown.

In view of the pathological importance of NF- $k B$ in inflammation and carcinogenesis, NF-kB inhibitors, particularly inhibitors of IKK2 are under active development for treatment of inflammatory diseases and cancer [7]. Druginduced liver injury is a leading cause of failed clinical trials and withdrawal of FDA-approved drugs from the market [8]. Thus, it is important to understand the role of IKK2-NF-kB in the regulation of genes important in inflammation, nutrient homeostasis, drug metabolism, and liver protection. The purpose of this study was to understand how moderate activation of IKK2-NF-kB in adult liver alters gene expression and pathophysiology. Surprisingly, adult male mice with adult-hepatocyte-specific activation of Ikk2 (Liv-Ikk2ca) had moderate increase in hepatic triglycerides as well as induction of certain classical NF-kB targets and important cytoprotective genes, but no changes in major markers of inflammation or fibrosis. Further study suggested that strong activation of IKK1-RelB, the anti-inflammatory alternative NF-kB pathway, as well as activation of liver $\mathrm{X}$ receptor (LXR), a nuclear receptor that promotes lipogenesis but exerts anti-inflammatory effects, might be the underlying mechanism of hepatic induction of cytoprotective genes and lipogenesis without apparent inflammation or fibrosis in these Liv-Ikk2ca mice.

\section{Methods}

Generation of mice with adult hepatocyte-specific expression of constitutive active Ikk2 (Liv-lkk2ca)

The R26Stop ${ }^{\mathrm{FL}} \mathrm{ikk} 2 \mathrm{ca}$ mice (Stock \# 008242, Jackson Laboratory) have a loxP-flanked STOP cassette that prevents the transcription of Ikk2ca from the endogenous Rosa26 gene locus [9]. Liv-Ikk2ca mice (Ikk2ca fl/+, Alb$\mathrm{cre} /+$ ) and wild-type littermates (Ikk2ca fl/+, Alb-cre/-) were generated by crossing R26Stop ${ }^{\mathrm{FL}} \mathrm{ikk} 2 \mathrm{ca}$ mice with Alb-cre mice (Stock \# 003574, Jackson Laboratory). In Liv-Ikk2ca mice, the removal of the STOP cassette by liver-specific expression of the Cre recombinase allows liver-specific expression of the Ikk2ca transgene driven by the endogenous Rosa26 promoter. Mice were fed rodent chow and allowed water and feed ad libitum. Liver and blood samples were collected from adult (3-month old) male Liv-Ikk2ca mice and the wild-type littermates $(N=6$ per group). Liver tissues were snap frozen in liquid nitrogen upon collection and stored at $-80{ }^{\circ} \mathrm{C}$ until use. To prepare serum samples, the clotted blood samples were centrifuged at $6000 \mathrm{rpm}$ for $10 \mathrm{~min}$ and the resultant supernatants were stored at $-80{ }^{\circ} \mathrm{C}$ until use. All animals received humane care and all animal procedures in this study were approved by the Institutional Animal Care and Use Committee (IACUC) of the SUNY Upstate Medical University.

RNA isolation and real-time PCR quantification of mRNA Total RNA from liver tissues was extracted by using RNA STAT-60 (Tel-Test, Friendswood, TX, USA). cDNA was produced by the use of High Capacity cDNA Reverse 
Transcription Kit (Applied Biosystems, Foster City, CA, USA) according to the manufacturer's instructions. The resultant cDNA was used for real-time PCR quantification of mRNA using $\mathrm{iQ}^{\mathrm{m}} \mathrm{SYBR}^{\circ}$ Green Supermix (Bio-Rad, Hercules, CA, USA) by MyiQ2 ${ }^{\text {ma }}$ Two-Color Real-Time PCR Detection System (Bio-Rad). The amount of mRNA was calculated using the comparative CT method, which determines the amount of target normalized to an endogenous reference, $\beta$-actin, with values of wild-type set as 1.0 .

\section{Western blot quantification of liver nuclear and cytosolic proteins}

Liver nuclear extracts were prepared with a nuclear extract kit (Marligen Biosciences, Inc., Rockville, MD). Liver lysates were prepared by homogenization of liver samples with RIPA buffer. Proteins in the liver nuclear extracts or lysates were resolved in sodium dodecyl sulphate-polyacrylamide gel electrophoresis. Western blot quantification of Ikk1, Ikk2, NF-kB subunits, and Foxo1 in liver nuclear and cytosolic extracts was carried out with the primary antibodies as follows: NF- $\mathrm{KB}$ p50 (sc-1190), p52 (sc-298), p65 (sc-109) and RelB (sc-226) from Santa cruz; IKK1 (\#2682), IKK2 (\#2370), Foxo1 (\#2880P) and histone H3 (\#4499) from Cell Signaling Technology, Inc; Glyceraldehyde 3-phosphate dehydrogenase (Gapdh) (HPA040067, Sigma-Aldrich). Western blot quantification of Scd1 in liver lysates was carried out with the primary antibody against Scd1 (\#2794S, Cell Signaling Technology). Primary antibodies were revealed with HRP-conjugated secondary antibodies (anti-rabbit IgG (W4011) or anti-goat IgG (V805A) from Promega) and ECL Western Blotting Substrate (W1015, Promega). ChemiDoc ${ }^{\mathrm{Tm}}$ XRS+ System (Bio-Rad) and Image Lab 4.0 software (Bio-Rad) were used to capture signals and determine signal intensities.

\section{Determination of DNA-binding of NF-kB p50 by chromatin immunoprecipitation quantitative PCR (ChIP-qPCR)}

The binding of NF-kB p50 subunit to DNA in mouse liver was quantified by ChIP-qPCR [10]. Briefly, chromatins $(5 \mu \mathrm{g})$ from livers of wildtype and Liv-Ikk2ca mice were used in ChIP assay using antibodies $(4 \mu \mathrm{g})$ against NF-кB p50 (sc-1190). The ChIPed DNA fragments were quantified by Qubit" DNA assay kit (Life Technologies), and the enrichment of DNA fragments that contain putative NF-kB binding sites in the gene promoter was quantified by qPCR reaction containing DNA fragments, $500 \mathrm{nM}$ primers (sequences in Additional file 1) and $\mathrm{iQ}^{\mathrm{m}}$ SYBR $^{\circ}$ Green Supermix by MyiQ2 ${ }^{\mathrm{mi}}$ Two-Color RealTime PCR Detection System.

Determination of serum levels of IL- 6 and MCP-1

Serum levels of IL-6 and Mcp-1 in wild-type and LivIkk2ca mice were quantified by Bio-Rad Bio-Plex Mouse
Cytokine Group I 2-plex Assay kit using the BioRad BioPlex 200 Luminex Instrument. Serum levels of IL-6 and Mcp-1 were calculated with standard curves of IL- 6 and Mcp-1 supplied in the kit.

$\mathrm{NAD}(\mathrm{P}) \mathrm{H}$ quinone oxidoreductase 1 (Nqo1) activity assay Liver homogenates were prepared in $25 \mathrm{mM}$ Tris- $\mathrm{HCl}$ ( $\mathrm{pH}$ 7.4) containing $250 \mathrm{mM}$ sucrose and $5 \mu \mathrm{M} \mathrm{FAD}^{+}$. After centrifugation of homogenates at $15,000 \mathrm{~g}, 10 \mu \mathrm{g}$ of supernatant proteins were used to determine Nqo1 activity as previously described using DCPIP as a substrate [11]. Nqo1 activity is described as the dicumarol inhibitable decrease in absorbance at $600 \mathrm{~nm}$, with values of wild-type group set as 1.0.

\section{Determination of lipids in mouse liver and serum}

Lipids from frozen liver tissue were prepared as described previously [12]. The lipid pellets were dissolved in a mixture of $270 \mu \mathrm{l}$ of isopropanol and $30 \mu \mathrm{l}$ of Triton $\mathrm{X}-100$. Triglycerides $(\mathrm{TG})$ and total cholesterol $(\mathrm{CHO})$ in liver and serum were determined using commercial triglyceride and cholesterol analytical kits with standards (Pointe Scientific, Canton, MI).

\section{Quantification of reduced glutathione (GSH), endogenous reactive oxygen species (ROS), lipid peroxidation, and hydroxyproline in mouse liver}

Liver homogenates were used to quantify GSH by Ellman's reagent and a GSH standard curve [13]. Hepatic levels of endogenous ROS were determined using $2^{\prime}, 7^{\prime}$ dichlorofluorescin diacetate as the fluorogenic probe and a standard curve of $2^{\prime}, 7^{\prime}$-dichlorofluorescein [14]. Lipid peroxidation was determined by quantifying thiobarbituric acid reactive substances (TBARS) using a standard curve of 1,1,3,3-Tetramethoxypropane. To determine liver fibrosis, hepatic levels of hydroxyproline were quantified following an improved method using Chloromine-T reagent and Ehrlich's reagent as well as a standard curve of hydroxyproline [15].

\section{Histopathological staining and analysis}

Liver samples were preserved in neutral buffered formalin (10 \%) before use. Formalin-fixed tissues were embedded in paraffin, sectioned $(5 \mu \mathrm{m})$, and stained with hematoxylin and eosin (H\&E). H\&E stained liver sections were evaluated by light microscopy at $200 \mathrm{X}$ magnification for evidence of hepatocyte apoptosis, inflammation, and fibrosis using a Leica DMI3000 B Inverted Light Microscope System with Leica DFC450 C Digital Microscope Camera (Leica Microsystems, Inc.).

\section{Statistical analysis}

All values are expressed as mean \pm S.E. The student's $t$-test was used to determine the statistical difference between 
Liv-Ikk2ca and wild-type samples (SigmaPlot 12.5). Statistical significance was set at $p<0.05$.

\section{Results}

Hepatic mRNA expression of genes important in NF-kB activation, inflammation, and fibrosis in Liv-lkk2ca mice It is noteworthy that the data on mRNA expression is based on total RNA extracted from whole liver and may be influenced by non-hepatocyte gene expression. The Ikk2ca protein is Flag-tagged [9]. Hepatic mRNA expression of the Ikk2ca transgene was determined using forward and reverse primers that specifically target the Flag tag and Ikk2 cDNA, respectively. Ikk2ca mRNA was very low in the wild-type (Ikk2ca fl/+, Alb-cre/-) livers (Mean Ct value $~ 30$ ), whereas the Ikk2ca mRNA expression levels in Liv-Ikk2ca mice (mean Ct value 24.7) appeared comparable to the expression levels of endogenous Ikk2 mRNA in wild-type mice (mean Ct value 24.3), estimated by the comparable $\mathrm{Ct}$ values of the Ikk2ca and mouse Ikk2 in these mice. Thus, hepatic expression of the Ikk2ca mRNA in the current Liv-Ikk2ca mice is likely lower than the two previous Liv-Ikk2ca mouse models in which the Ikk2ca transgene was driven by strong promoters from albumin and liver activator protein $[5,6]$. Expectedly, hepatic mRNA expression of Ikk2 and classical targets of NF-kB activation, namely $\mathrm{IkB \alpha}$, serum amyloid a1 (Saa1), intercellular adhesion molecule 1 (Icam1), Bcl-x, and Akt1 [1,3] were all significantly higher in 12-week-old male Liv-Ikk2ca mice than wildtype littermates (Fig. 1a). Conversely, Liv-Ikk2ca mice had comparable Gadd45b, RelA/p65, and Nfkb1 (p50), but moderately higher Ikk1 and much higher (6.9 fold) RelB (Fig. 1a). Interestingly, Liv-Ikk2ca mice had much higher (5.5 fold) Ikbke and $95 \%$ higher NF-kB inducing kinase (NIK) which activates IKK1 [16] (Fig. 1a). Moreover, Liv-Ikk2ca mice had markedly higher cytokines lipocalin-2 (Lcn2, 106 fold) and A20 (9.4 fold) (Fig. 1a). Lcn2, an antimicrobial protein, protects endotoxin-induced sepsis [17] and diet-induced insulin resistance [18]. A20, an early NF$\mathrm{kB}$-responsive gene, has anti-inflammatory effects via negative feedback regulation of the classical NF-kB pathway [19] but activation of the alternative NF-kB pathway [20].

Surprisingly, markers of inflammation and fibrosis, namely Tnfo, IL-1 $\beta$, IL-6, chemokine (C-C motif) ligand 2/monocyte chemotactic protein 1 (Ccl2/Mcp-1), Ccl5, Ccl19, Ccl20, NO synthase 2 (Nos2), transforming growth factor $\beta$ (Tgf $\beta), \alpha$-smooth muscle actin $(\alpha-$ Sma), and collagen 1a1 (Col1a1), all remained unchanged in LivIkk2ca mice (Fig. 1b), which is in a sharp contrast to marked induction of these genes as well as inflammation and fibrosis in adult mice with neonatal hepatocytespecific activation of IKK2 [5]. In a previous study when hepatic expression of Ikk2ca was driven by the albumin promoter, although hepatic mRNA expression of IL-1 $\beta$ and IL- 6 were strongly increased by 2.7 and 7.8 fold, respectively, blood levels of IL-1 $\beta$ remained unchanged whereas blood levels of IL- 6 only doubled in those mice [6]. Consistent with the lack of increase in hepatic mRNA expression of inflammatory cytokines/chemokines, blood levels of IL- 6 remained below the detection limit in wildtype and Liv-Ikk2ca mice, and there was no difference in blood levels of Mcp-1 between wild-type $(96 \pm 12 \mathrm{pg} / \mathrm{ml}$ ) and Liv-Ikk2ca mice $(67 \pm 8 \mathrm{pg} / \mathrm{ml})$.

\section{Liver histopathology in Liv-lkk2ca mice}

Histologically, the livers of wild-type (Fig. 2a) and LivIkk2ca (Fig. 2b) mice were undistinguishable. There were no signs of infiltration of inflammatory cells or fibrosis in livers of Liv-Ikk2ca mice (Fig. 2b), which is consistent with the lack of induction of proinflammatory and fibrotic genes in these mice (Fig. 1).

\section{Hepatic mRNA expression of key antioxidative genes in Liv-Ikk2ca mice}

Liv-Ikk2ca mice had 120, 85, and $80 \%$ higher expression of antioxidative genes Nqo1, superoxide dismutase 2 (Sod2), and glutathione peroxidase 1 (Gpx1), respectively (Fig. 3a). Conversely, Liv-Ikk2ca mice had similar Sod1, Nqo2, catalase (Cat), heme oxygenase-1 (Ho-1), epoxide hydrolase 1 (Ephx1), as well as glutamate-cysteine ligase catalytic subunit (Gclc) and modifier subunit (Gclm), key enzymes of glutathione synthesis.

To determine whether changes in mRNA expression translated into changes in protein expression and function, we determined Nqo1 activities in liver homogenates. The 1.2 fold higher mRNA expression of Nqo1 (Fig. 3a) was associated with similarly $94 \%$ higher activities of Nqo1 in livers of Liv-Ikk2ca mice than wild-type mice (Fig. 3b).

\section{Hepatic mRNA expression of genes important in metabolism of glucose, lipids, cholesterol, and bile acids (BAs) in Liv-lkk2ca mice}

Surprisingly, Liv-Ikk2ca mice and wild-type mice had similar expression of key enzymes for gluconeogenesis and glucose utilization, namely Pepck, G6pc, and glucokinase (Gck) (Fig. 4a). Conversely, Liv-Ikk2ca mice had 58 $\%$ higher glycogen synthase 2 (Gys2), a key enzyme for glycogen synthesis. Therefore, IKK2 activation in normal adult hepatocytes appears to produce a cytoprotective gene expression profile without apparent signs of inflammation, induction of gluconeogenic genes, or fibrosis.

Liv-Ikk2ca mice have $83 \%$ higher fatty acid synthase (Fasn) and 1.2-fold higher CD36, a key uptake transporter of fatty acids (Fig. 4a). Stearoyl-CoA desaturase 1 (Scd1) is rate-limiting for the biosynthesis of monounsaturated fatty acids, whereas apolipoprotein E (ApoE) is essential for normal catabolism of triglyceride-rich lipoproteins. Liv- 

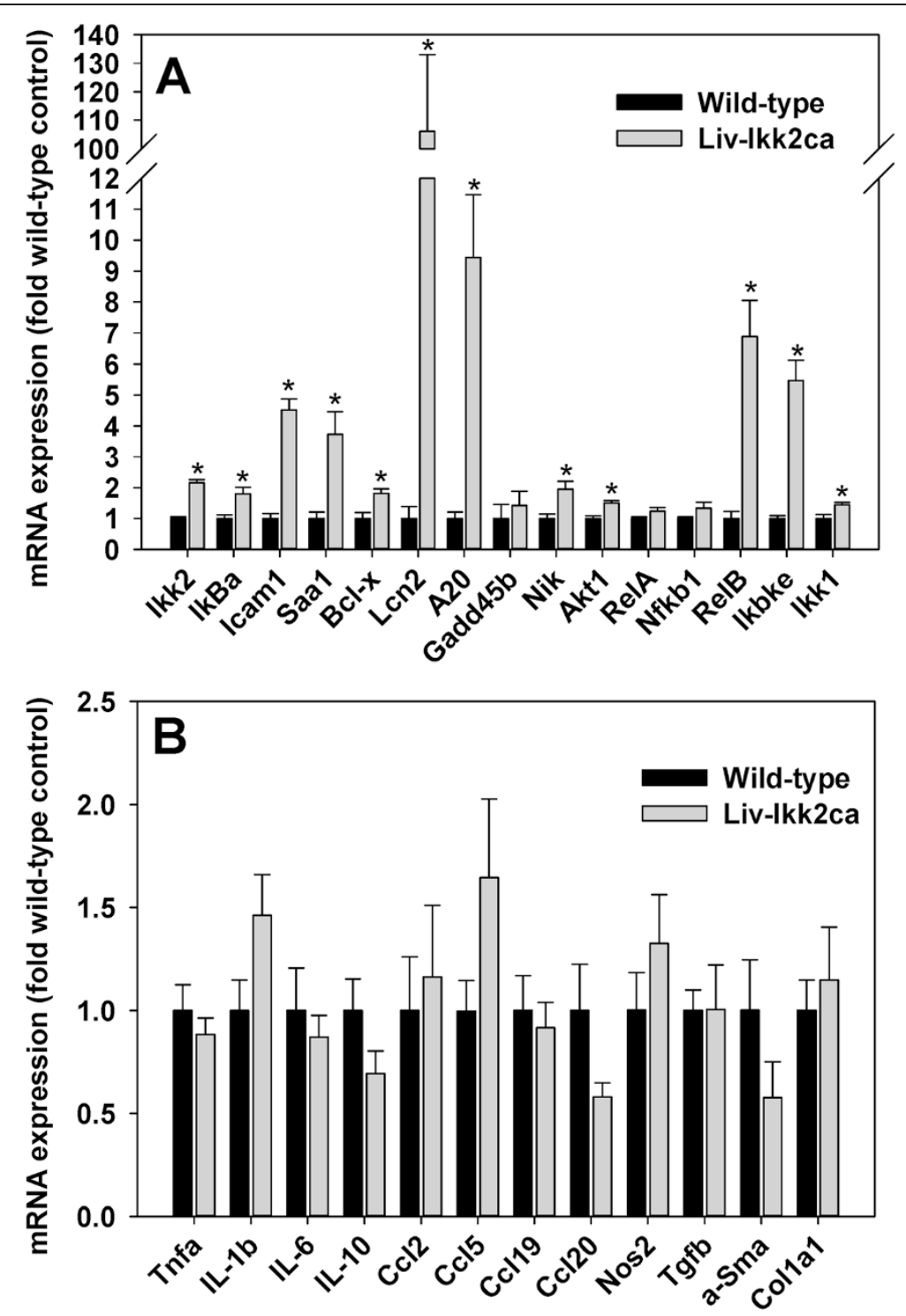

Fig. 1 Hepatic mRNA expression of genes important in the IKK-NF-kB pathways, inflammation and fibrosis in adult male mice with hepatocyte-specific activation of Ikk2 (Liv-lkk2ca). a IKK-NF-kB pathways; and $\mathbf{b}$ inflammation and fibrosis. $N=6$ per group, mean \pm SE. ${ }^{*} p<0.05$ versus wild-type mice

Ikk2ca mice had 120 and $28 \%$ higher Scd1 and ApoE, respectively. Additionally, Liv-Ikk2ca mice had similar acylCoA oxidase 1 (Acox1), a key enzyme in peroxisomal fatty acid oxidation, but $60 \%$ lower cytochrome P450 4 a14 (Cyp4a14) and a trend of lower Cyp4a12, enzymes for microsomal fatty acid oxidation (Fig. 4a). Thus, compared to wild-type mice, livers of Liv-Ikk2ca mice had higher expression of genes important for the uptake (CD36) and synthesis (Fasn \& Scd1) of fatty acids, but lower expression of genes for microsomal fatty acid oxidation (Cyp4a14).

Cyp7a1 and Cyp8b1 are two key enzymes in the classic pathway, whereas Cyp27a1 and Cyp7b1 are two key enzymes in the alternative pathway of BA biosynthesis from cholesterol. Liv-Ikk2ca mice had 80 \% higher Cyp7a1 and $44 \%$ lower Cyp7b1 (Fig. 4b), but similar Cyp8b1 and
Cyp27a1 (Additional file 2). Liv-Ikk2ca mice had $40 \%$ higher Abca1, which pumps cholesterol/phospholipids into circulation. Additionally, Liv-Ikk2ca mice had 54\% higher BA CoA: amino acid $\mathrm{N}$-acyltransferase (Baat), a key enzyme for BA conjugation, and $31 \%$ higher Taurine transporter (TauT). Therefore, compared to wild-type mice, livers of Liv-Ikk2ca mice had higher mRNA expression of the key genes for BA biosynthesis (Cyp7a1) and BA conjugation (Baat and TauT).

Liv-Ikk2ca mice had $40 \%$ lower expression of uptake transporter organic anion-transporting polypeptide 1a1 (Oatp1a1) but $45 \%$ higher efflux transporter Abcg2 and $57 \%$ higher multi-drug resistance 2 (Mdr2), the biliary efflux transporter for phospholipids (Fig. 4b). Conversely, Liv-Ikk2ca mice and wild-type mice had comparable 


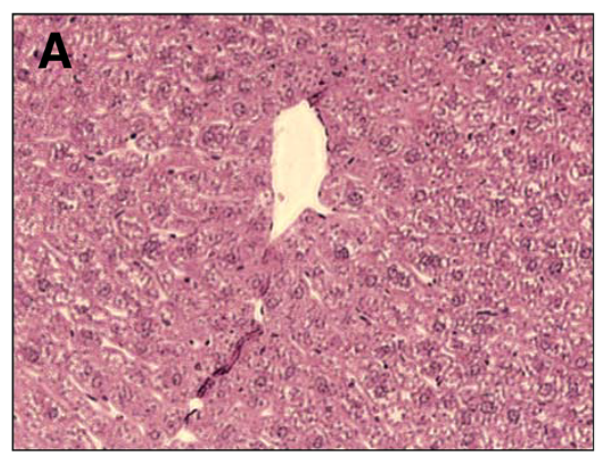

Wild-type

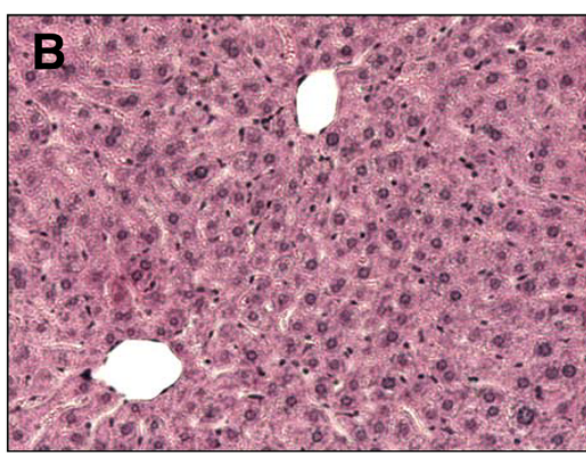

Liv-lkk2ca

Fig. 2 Liver histopathology in adult male mice with hepatocyte-specific activation of Ikk2 (Liv-lkk2ca). a wild-type mice; and $\mathbf{b}$ Liv-lkk2ca mice. Hematoxylin and eosin (H\&E) staining of paraffin embedded liver sections (5 $\mu \mathrm{m}$ and $200 \times$ magnification)

mRNA expression of other major BA uptake and efflux transporters (Additional file 2). In summary, Liv-Ikk2ca mice may have increased classic pathway of BA biosynthesis (by Cyp7a1), higher capacity for BA conjugation (by Baat and TauT), and higher biliary output of BAs (by Mdr2 and Abcg2).

To determine whether changes in mRNA expression translated into changes in protein expression, we used Western blot to determine Scd1 protein levels in liver homogenates. The 1.2 fold higher mRNA expression of Scd1 (Fig. 4a) was associated with similarly $78 \%$ higher Scd1 protein in livers of Liv-Ikk2ca mice than wild-type mice (Fig. 4c \& d).

\section{Hepatic and circulating levels of triglycerides and} cholesterol in Liv-lkk2ca mice

Consistent with higher hepatic expression of lipogenic genes, hepatic triglycerides were $61 \%$ higher in LivIkk2ca mice than in wild-type mice (Fig. 5a). Conversely, Liv-Ikk2ca mice had comparable cholesterol in liver
(Fig. 5a) and similar serum levels of total cholesterol and triglycerides (data not shown).

\section{Hepatic levels of GSH, endogenous ROS, lipid} peroxidation, and hydroxyproline in Liv-lkk2ca mice Activation of NF-kB has been associated with oxidative stress and steatohepatitis. However, we found that despite moderately elevated hepatic triglycerides in Liv-Ikk2ca mice, hepatic levels of GSH, endogenous ROS, and lipid peroxidation (MDA) remained unchanged in Liv-Ikk2ca mice compared to wild-type mice (Fig. 5b \& c). Additionally, consistent with a lack of induction of fibrogenic genes, hepatic levels of hydroxyproline, a marker of fibrosis, remained unchanged in Liv-Ikk2ca mice (Fig. 5d).

Hepatic mRNA expression of major drug-metabolizing enzymes in Liv-lkk2ca mice

Activation of NF-kB has been implicated in downregulation of drug-processing genes (DPGs) during inflammation [21]. Thus, we determined hepatic mRNA expression of major DPGs. Liv-Ikk2ca mice and wild-
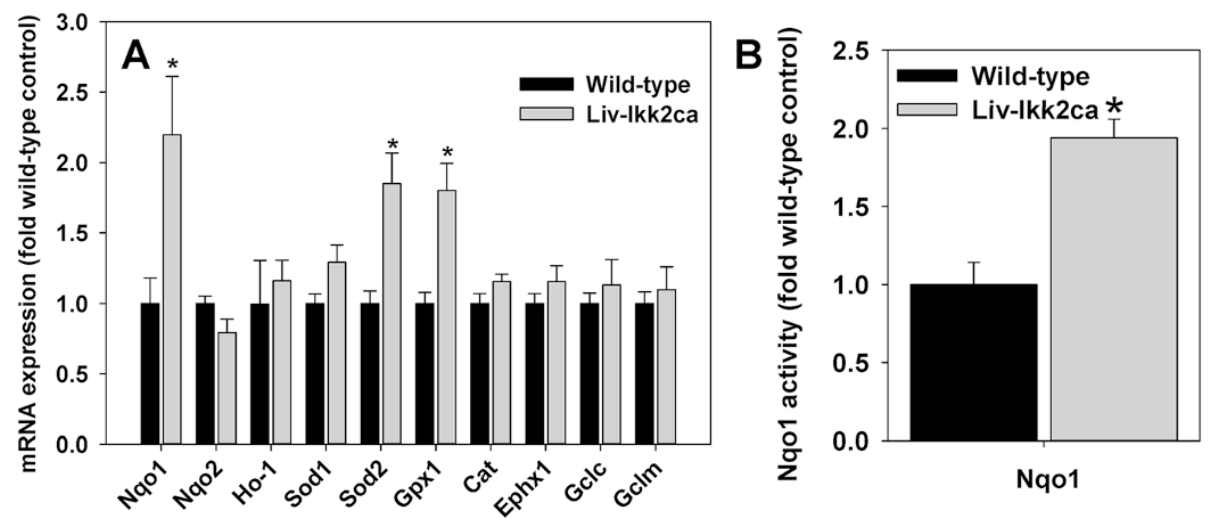

Fig. 3 Hepatic mRNA expression of key antioxidative genes and Nqo1 activities in adult male mice with hepatocyte-specific activation of Ikk2 (Liv-Ikk2ca). a mRNA expression of antioxidative genes; and $\mathbf{b}$ Nqo1 activities. $N=6$ per group, mean \pm SE. ${ }^{*} p<0.05$ versus wild-type mice 

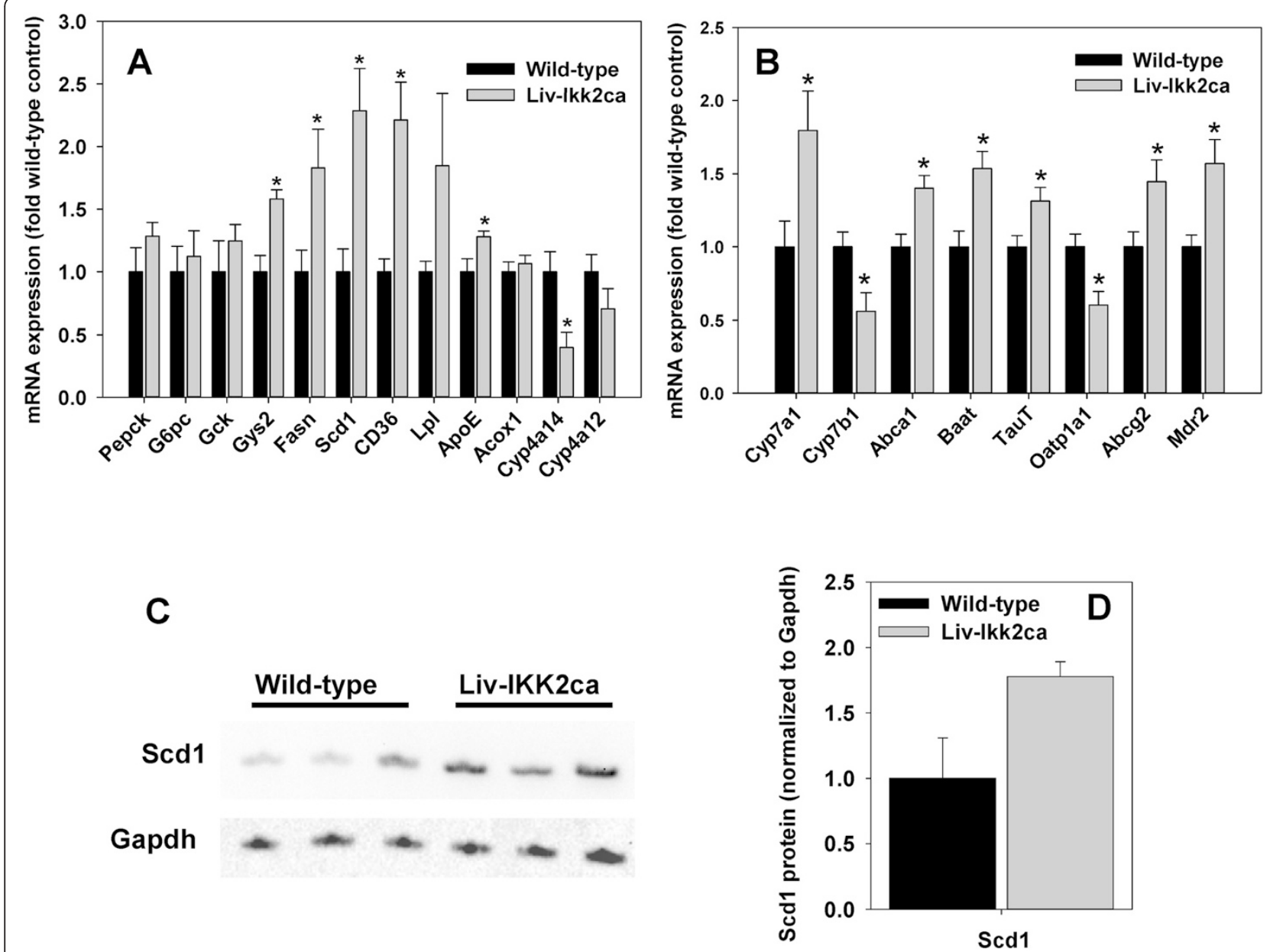

Fig. 4 Hepatic expression of genes important in metabolism of glucose and lipids as well as cholesterol and bile acids in adult male mice with hepatocyte-specific activation of Ikk2 (Liv-lkk2ca). a mRNA expression of genes in glucose and lipid metabolism; $\mathbf{b}$ mRNA expression of genes in cholesterol and bile acid metabolism. $N=6$ per group, mean \pm SE. ${ }^{*} p<0.05$ versus wild-type mice. $\mathbf{c} \& \mathbf{d}$ Hepatic protein levels of Scd 1 in adult male Liv-lkk2ca mice. The densities of Scd1 in the gel image (top) were normalized to Gapdh (bottom). $N=3$ per group, mean $\pm S E$

type mice had similar expression of most major Cyps, (Additional file 3A). However, Liv-Ikk2ca mice had 30 and $40 \%$ lower Cyp2c44 and Cyp2e1, respectively, but $41 \%$ higher Cyp3a11 (Fig. 6), the most predominant Cyp3a isoform in mouse liver [22].

Liv-Ikk2ca mice and wild-type mice had similar expression of most major UDP-glucuronosyltransferases (Ugts) and sulfotransferases (Sults) (Additional file 3B). Conversely, Liv-Ikk2ca mice had 4.2 fold, $40 \%$, and 21 fold higher Ugt1a9, Ugt2b34, and Sult1e1, respectively, and $69 \%$ higher 3 ' -phosphoadenosine 5 ' -phosphosulfate synthetase 2 (Papss2) (Fig. 6), the major enzyme for PAPS biosynthesis in liver [23].

Liv-Ikk2ca mice and wild-type mice had similar expression of most major hepatic glutathione $S$-transferases (Gsts) [23], (Additional file 3C). Conversely, Liv-Ikk2ca mice had $60 \%$ higher Gstm5 and $46 \%$ higher Gsto1, but $30 \%$ lower Gstp1 (Fig. 6). Thus, IKK2 activation in adult mouse hepatocytes does not down-regulate most major DPGs.

\section{Hepatic expression of essential transcription factors in Liv-lkk2ca mice}

Transcription factors hepatocyte nuclear factor $1 \alpha$ $(\mathrm{HNF} 1 \alpha), \mathrm{HNF} 4 \alpha, \mathrm{C} / \mathrm{EBP} \alpha, \mathrm{C} / \mathrm{EBP} \beta$, farnesoid $\mathrm{X}$ receptor (FXR), liver X receptor $\alpha(\mathrm{LXR} \alpha), \mathrm{LXR} \beta$, and peroxisome proliferator-activated receptor $\gamma$ (PPAR $\gamma$ ) as well as the co-activator PPAR $\gamma$ coactivator $1 \alpha(\mathrm{PGC} 1 \alpha)$ and the coinhibitor small heterodimer partner (SHP) are essential for hepatic basal expression of genes important for nutrient and xenobiotic metabolism [24, 25]. Many of them were modestly higher in Liv-Ikk2ca mice, such as Hnfla (45\%), Cebpa (44\%), Cebpb (46\%), and Fxr (71 \%) (Fig. 8a). Interestingly, Liv-Ikk2ca mice had 59, 78, and $32 \%$ higher expression of 3 lipogenic nuclear receptors, namely Ppary, Lxr $\alpha, \operatorname{Lx} \beta$, respectively, and tended to have 

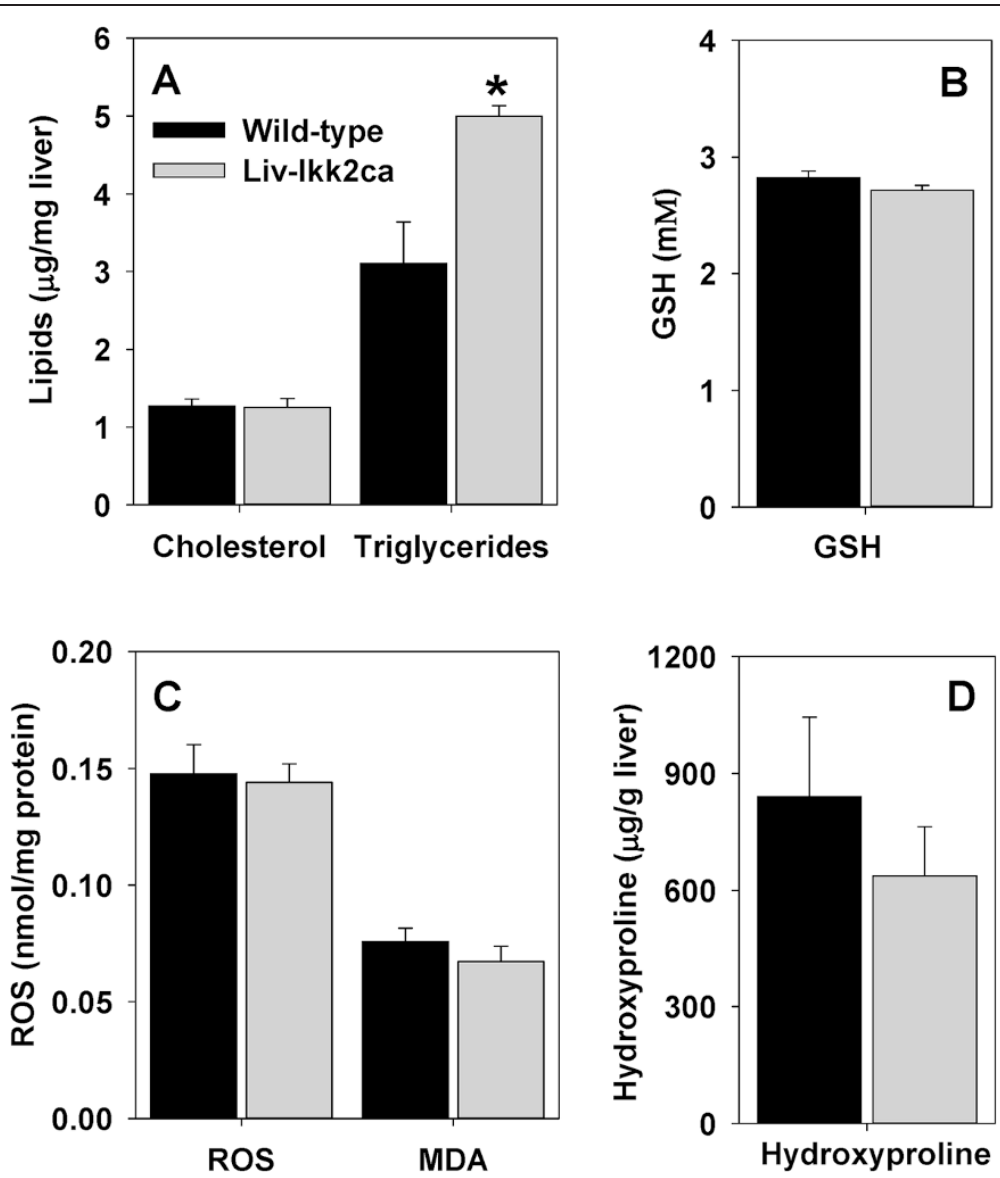

Fig. 5 Hepatic levels of triglycerides, cholesterol, reduced GSH, endogenous reactive oxygen species (ROS), malondialdehyde (MDA), and hydroxyproline in adult male mice with hepatocyte-specific activation of Ikk2 (Liv-Ikk2ca). a triglycerides and cholesterol; $\mathbf{b}$ reduced GSH; c endogenous ROS and MDA; and $\mathbf{d}$ hydroxyproline. $N=6$ per group, mean \pm SE. ${ }^{*} p<0.05$ versus wild-type mice

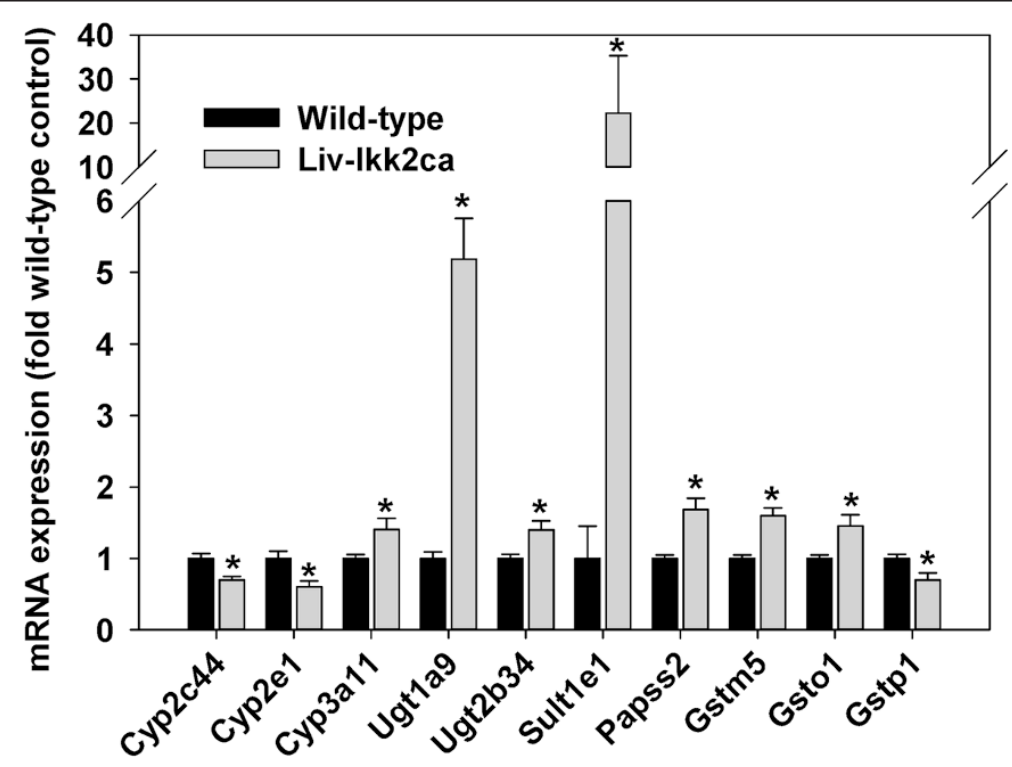

Fig. 6 Hepatic mRNA expression of major cytochome P450s (Cyps) and Phase-Il enzymes in adult male mice with hepatocyte-specific activation of Ikk2 (Liv-Ikk2ca). $N=6$ per group, mean \pm SE. ${ }^{*} p<0.05$ versus wild-type mice 
higher $(47 \%)$ lipogenic transcription factor Srebp-1c (Fig. 7a).

Xenobiotic receptors, namely aryl hydrocarbon receptor (AhR), constitutive active receptor (CAR), Pregnane $\mathrm{X}$ receptor (PXR), PPAR $\alpha$, and nuclear factor (erythroidderived 2)-like 2 (NRF2) are very important in hepatic induction of DPGs by xenobiotics, and retinoid X receptor $\alpha(\mathrm{RXR} \alpha)$ is the obligatory heterodimer partner for FXR, CAR, PXR, and PPARs [26]. Glucocorticoid receptor (GR), c-Jun, and c-Myc are important in inflammation and stress responses. Liv-Ikk2ca mice had 48, 36, and $32 \%$ higher AhR, Nrf2, and Gr, respectively, but similar Rxra, Car, Pxr, c-jun, and c-Myc (Fig. 7b).

Because different NF-kB subunits have differential effects on gene expression, we used Western blot to quantify hepatic nuclear and cytosolic protein levels of Ikk2, Ikk1, and major NF-kB subunits (Fig. 8). The Ikk2ca protein was Flag-tagged. Interestingly, an additional band was detected by Ikk2 antibody only in the cytosol of LivIkk2ca mice, which might be the Ikk2ca protein and/or post-translationally modified Ikk2 protein (Fig. 8a, upper band). Nuclear levels of Ikk2 and Ikk1 were 100 and $88 \%$ higher in Liv-Ikk2ca mice than wild-type mice, respectively (Fig. 8b). Nuclear levels of p65, p50, and RelB were 1.2-, 2.3-, and 8.6-fold higher in Liv-Ikk2ca mice (Fig. 8b), whereas p65, p50 and p52 were hardly detectable in the cytosol of both Liv-Ikk2ca mice and wild-type mice (Fig. 8a). Conversely, nuclear and cytosolic levels of precursors p100 and p105 remained unchanged (Fig. 8), and nuclear Foxo1, a transcription factor important in the regulation of insulin signaling and inflammation $[27,28]$ was very low in both strains (data not shown). Interestingly, p105, but not p100, was clearly present in the nuclei of both strains (Fig. 8b), whereas p52 appeared to be present at much higher levels than p50 in the nuclei in wild-type livers (Fig. 8b), which is consistent with high hepatic basal activity of Ikk1 [29].
Binding of NF-kB p50 to the promoter of genes altered in livers of Liv-lkk2ca mice

To determine whether increases in the nuclear NF-kB subunits (Fig. 8b) translate into increases the DNA-binding of NF-kB, we used ChIP-qPCR to determine DNA-binding of p50 in livers of Liv-Ikk2ca mice. The total amount of DNA fragments pulled down by the p50 antibody was 12.4 fold higher in Liv-Ikk2ca mice than wild-type mice (Fig. 9a). Additionally, results of ChIP-qPCR showed that the binding of p50 to the proximal promoters of Ikba, Saa1, Icam1, Nqo1, Cyp2e1, and Cyp3a11 were 5-9 fold higher in LivIkk2ca mice than wild-type mice (Fig. 9b).

\section{Discussion}

Two recent studies demonstrate that neonatal hepatocytespecific superactivation of IKK2-NF-kB causes progressive inflammation and liver fibrosis at adulthood [5], whereas hepatocyte-specific activation of IKK2-NF-kB by transgenic expression of Ikk2ca driven by a strong albumin promoter causes inflammation and insulin resistance without liver fibrosis [6]. The present study demonstrates that hepatocyte-specific expression of Ikk2ca driven by a moderate endogenous Rosa26 promoter produces a cytoprotective gene expression profile, without apparent signs of hepatic inflammation or fibrosis in mice. However, these Liv-Ikk2ca mice have moderate increase in lipogenesis. Currently, it remains unknown the underlying mechanism of the marked differences in gene expression and liver pathophysiology between our Liv-Ikk2ca mice and the two previous mouse models $[5,6]$. In all these three models, mice with liver-specific activation of Ikk2 were examined at around 12 weeks of age, and thus the differences in hepatic gene expression and pathophysiology among these mouse models are unlikely due to differences in age. Compared to the two previous mouse models $[5,6]$, our Liv-Ikk2ca mice do not have higher expression of many cytokines (e.g. TNF $\alpha$, IL-1 $\beta$, and IL-6) or
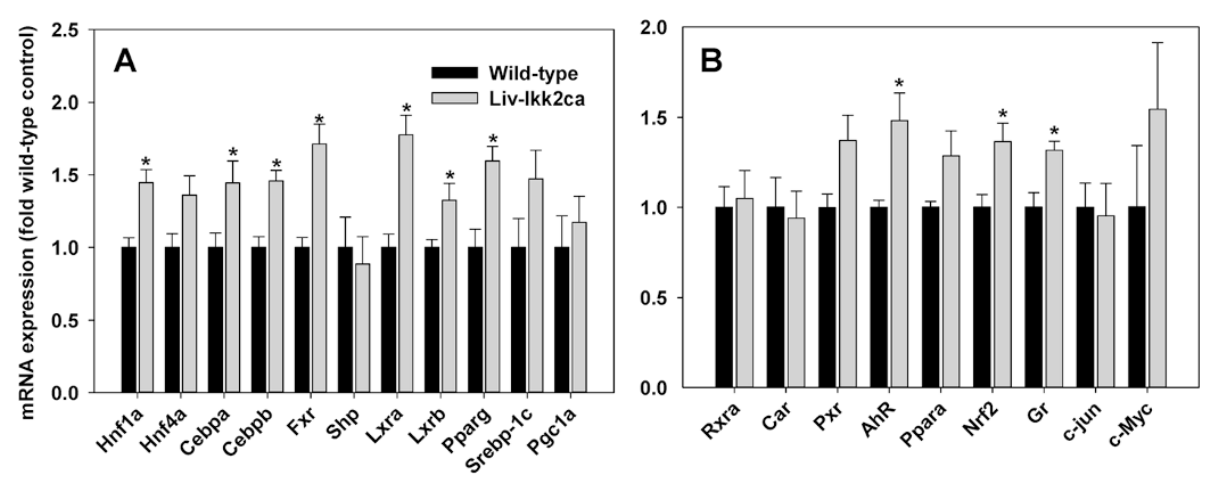

Fig. 7 Hepatic mRNA expression of key transcription factors in adult male mice with hepatocyte-specific activation of Ikk2 (Liv-Ikk2ca). $N=6$, mean \pm SE. * $p<0.05$ versus wild-type mice 


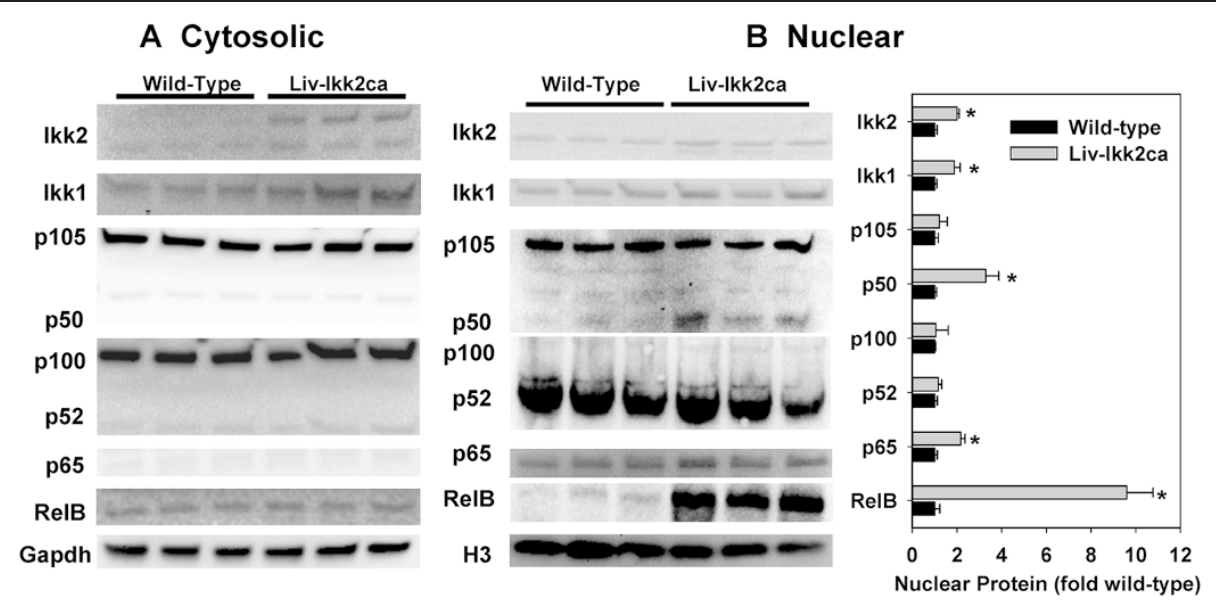

Fig. 8 Western blot quantification of cytosolic and nuclear protein levels of Ikk and NF-kB subunits in adult male mice with hepatocyte-specific activation of Ikk2 (Liv-Ikk2ca). a cytosol; b nuclei. The densities of Ikk and each NF-kB subunit in the gel image (top) were normalized to Gapdh (a) or histone $\mathrm{H} 3$ (b). $N=3$ per group, mean \pm SE. ${ }^{*} p<0.05$ versus wild-type mice

chemokines (Mcp-1/Ccl2, Ccl5, and Ccl20), suggesting that these 3 Ikk2ca mouse models have significant difference(s) in the activation of the upstream transactivator(s) of these cytokines and chemokines.

A major potential mechanism of differences in hepatic gene expression and pathophysiology between the current mouse model and the two previous mouse models is differences in the magnitude of activation of IKK2-NF-kB pathway. In fact, the gene-dosage effect of Ikk2 activation on liver pathophysiology has been demonstrated in the study of mice in which the Ikk2ca transgene is driven by a strong albumin promoter [6]. Glucose intolerance and insulin resistance are more severe in the homozygous transgenic mice (with two alleles of Ikk2ca transgene) than the hemizygous transgenic mice [6]. In the model of neonatal hepatocyte-specific activation of IKK2-NF-kB, the IKK2ca protein is highly expressed in the transgenic liver, at levels much higher than the control mice [5]. In contrast, in the mouse model that hepatic expression of Ikk2ca is driven by an albumin promoter, hepatic IKK2ca protein was only moderately increased, judged from the Western blot data [6]. In the present study, hepatic expression of Ikk2ca is driven by the endogenous Rosa26 promoter [9], and hepatic mRNA and protein expression of Ikk2 in Liv-Ikk2ca mice are only moderately higher than wild-type mice (Fig. 8), which will translate into a moderate activation of the Ikk2NF-kB pathway in mouse liver. Because of the putative large differences in the magnitude of hepatic expression of Ikk2ca protein, results from the previous two Liv-Ikk2ca mouse models (using promoters much stronger than the endogenous Ikk2 promoter) may reflect superactivation of Ikk2-NF-kB under certain pathological conditions $[5,6]$, whereas results from the current Liv-Ikk2ca mouse model (using a moderate promoter weaker than the endogenous Ikk2 promoter) may reflect physiological activation of Ikk2 under certain pathophysiological conditions.

The high basal nuclear p52 and strong induction of RelB (Fig. 8b) indicate that the IKK1-regulated alternative NF-kB pathway via RelB/p52 is strongly activated in livers of Liv-Ikk2ca mice. The higher nuclear $\mathrm{p} 50$ protein (Fig. 8b) without higher mRNA expression of Nfkb1 (Fig. 1a), the precursor of p50 in Liv-IKK2ca mice suggests a preferential activation of p50 over p65 in the classical NF-kB signaling pathway. In contrast, there is
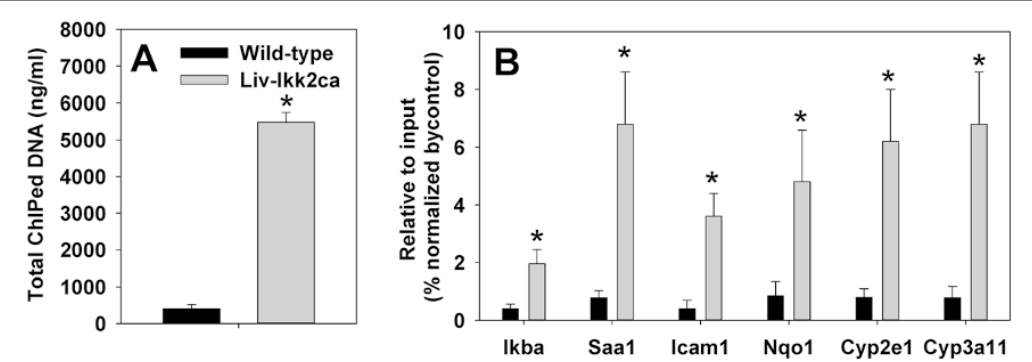

Fig. 9 ChIP-qPCR determination of binding of NF-kB p50 to proximal promoters of genes altered in livers of adult male mice with hepatocyte-specific activation of Ikk2 (Liv-lkk2ca). a total amount of ChIPed DNA; $\mathbf{b}$ qPCR quantification of enrichment of DNA fragments that contain putative NF-kB binding site. $N=3$ per group, mean \pm SE. ${ }^{*} p<0.05$ versus wild-type mice 
marked increase in nuclear translocation of p65 in adult livers of mice with neonatal activation of IKK2, which is associated with inflammation and fibrosis [5]. Consistently, mice with knockin of constitutively active p65 develop systemic inflammation and liver fibrosis [30]. The NF-kB p50 can form heterodimer with both p 65 and RelB, and the p65/p50 and RelB/p50 heterodimers have distinct target genes and physiological functions. The RelB/p50 heterodimer inhibits TNF $\alpha$ expression [31]. Importantly, RelB and IKK1 are essential in anti-inflammation. RelB knockout mice develop spontaneous multiorgan inflammation [32], which is worsened by concomitant loss of p50 [33]. During endotoxin tolerance, induction of RelB is necessary and sufficient to silence proinflammatory genes [34]. IKK1 is constitutively active in unstimulated adult hepatocytes [29], which is consistent with the high nuclear levels of p52 in wild-type livers (Fig. 8b). Loss of IKK1 prolongs the activation of IKK2 and promotes inflammation [35]. IKK1 accelerates the removal of RelA/p50 subunits from proinflammatory gene promoters to limit NF-kB activation [35]. Importantly, in unstimulated cells, assembly of IKK1 with IKK2 into a heterodimeric complex inhibits the high intrinsic activity of IKK2 [36].

It is well established that NF-kB activity is very low in unstressed adult liver [37]; however, the underlying mechanism remains elusive. The p105 precursor of p50, encoded by Nfkb1, plays a key role in inhibition of NFkB activation. Previous cellular study showed that p105 is exclusively located in the cytosol [38]. Interestingly, we found that p105 is also readily detectable in the nuclei of unstressed adult liver (Fig. 8b). Thus, the high basal activities of Ikk1/p52 and nuclear p105 may help maintain the basal activities of NF-kB at low levels in unstressed adult liver, and the further induction and activation of Ikk1 and RelB after a moderate activation of Ikk2 by the Ikk2ca protein may play a key role in preventing the overactivation of IKK $2 / \mathrm{NF}-\mathrm{kB}$ and resultant induction of proinflammatory genes (e.g. IL-6 and Mcp-1) in Liv-Ikk2ca mice.

FOXO1 inhibits insulin sensitivity, and FOXO1 synergizes with NF-kB p65 and/or p50 to induce proinflammatory IL-1 $\beta$, IL-6, and CCL20 [28, 39, 40], genes induced in adult mice with neonatal liver-specific activation of Ikk2 [5] but not in the present Liv-Ikk2ca mice (Fig. 1). Importantly, FOXO1 dramatically induces CCL20 in an NF-kBdependent manner in HepG2 cells [39]. Moreover, FOXO1 induces CCL2 and IL-6 [41]. FOXO1 protein is abundantly present in the nucleus of neonatal liver, but only at very small amount in the nucleus of adult liver [42]. Additionally, FOXO1 is markedly activated during fasting [43], a condition used for the study of glucose intolerance and insulin resistance [6]. The Liv-IKK2ca mice were not fasted before euthanasia in this study. Taken together, we propose a novel hypothesis that the magnitude of IKK2 activation, through interaction with FOXO1 and IKK1, play key roles in determining the protective versus detrimental effect of IKK2-NF-kB activation in liver. When IKK2 is activated moderately in normal adult liver with normal insulin signaling, active IKK1 balances the NF-kB signaling by activating $\mathrm{p} 52 /$ RelB but preventing overactivation of $\mathrm{p} 65$, and the low FOXO1 activity also prevents induction of proinflammatory cytokines/chemokines, resulting in induction of cytoprotective genes without inflammation and fibrosis, as observed in the present study (Fig. 10). Conversely, when IKK2 is superactivated in fasting liver or neonatal liver, where IKK1 is low and FOXO1 activity is high [42], FOXO1 synergizes with p65/p50 to cause insulin resistance and induce proinflammatory IL-1 $\beta$, IL-6, CCL2, and CCL20, resulting in progressive inflammation and/or liver fibrosis [5].

It is noteworthy that Ikk2 has NF-kB-independent functions in immunity. Ikk2 can phosphorylate tuberous sclerosis 1 , resulting in activation of the mTOR pathway [44]. mTOR has multifunctional role in inflammation; inhibition of mTOR causes distinct inflammatory side effects such as fever, pneumonitis, glomerulonephritis or anemia of chronic disease [45]. Thus, the NF-kB-independent function of IKK2, such as activation of the mTOR pathway, might suppress inflammation in the context of low expression of activated Ikk2.

Previous in vitro studies suggest that activation of NF$\mathrm{kB}$ plays a key role in the down-regulation of DPGs during inflammation [46]. The present study demonstrates that moderate activation of IKK2-NF-kB by Ikk2ca does not down-regulate most major DPGs. Conversely, activation of NF-kB induces Cyp3a11 whose human ortholog CYP3A4 plays a key role in the metabolism of numerous drugs [47]. The down-regulation of DPGs by NF-kB in vitro is ascribed to direct binding of p65 to promoters and/or indirect inhibition of DPGs via inhibitory interactions of p65 with other key transcription factors such as HNF4 $\alpha, G R$, PXR, and CAR $[46,48]$. In the present study, nuclear p65 is increased moderately whereas p50 and RelB are increased more markedly (Fig. 8b), and hepatic expression of transcription factors essential for DPG expression are either unaltered or induced in LivIkk2ca mice (Fig. 7). Thus, activation of IKK2-NF-kB in the absence of overt inflammation does not downregulate most DPGs; however, the role of superactivation of NF-kB p65 in down-regulation of DPGs during inflammation cannot be excluded.

In addition to inflammation, the IKK2-NF-kB pathway can be activated by diverse stress signaling such as oxidative stress and xenobiotic exposure, and activation of $\mathrm{NF}-\mathrm{kB}$ often protects against oxidative stress [49]. Interestingly, our study provides the first evidence that moderate activation of IKK2 in normal adult mouse liver down-regulates Cyp2e1, Cyp4a14, and Gstp1 (Fig. 6), 


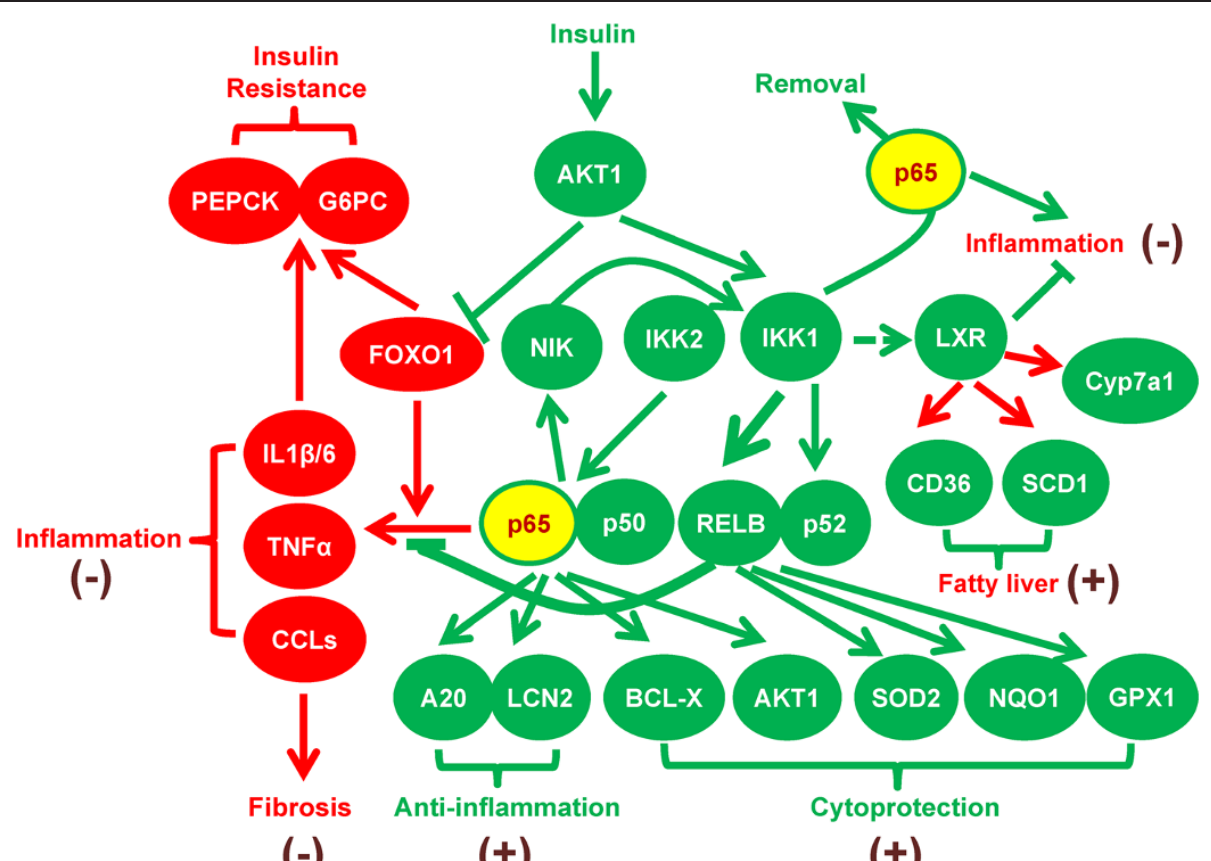

$(-)$

$(+)$

$(+)$

Fig. 10 Diagram that summarizes the possible underlying mechanisms of key changes in gene expression and pathophysiology in adult male mice with hepatocyte-specific activation of Ikk2 (Liv-lkk2ca). Genes that are active or induced in Liv-lkk2ca mice are in green shape, whereas genes that are inactive or unchanged in Liv-lkk2ca mice are in red shape. Pathways/responses that are activated in Liv-lkk2ca mice are marked with (+), whereas pathways/responses that are inhibited or unchanged in Liv-lkk2ca mice are marked with (-)

genes involved in generating oxidative stress and liver injury, but induces antioxidative genes Nqo1, Sod2, Gpx1 (Fig. 3a), and Abcg2 (Fig. 4b) as well as cytoprotective genes Bcl-xl and Akt1 (Fig. 1). Activation of NF-kB and/or induction of Nrf2 (Fig. 7) may be the underlying mechanism of induction of these cytoprotective genes. For example, Sod2 is a direct target of RelB [50], and Nqo1, Sod2, Gpx1, and ABCG2 are known NF-kB target genes in cellular studies $[49,51]$. Cyp4a14 is dramatically induced in livers of Nrf2-null mice [12]; thus, the moderate induction of Nrf2 might play a role in the down-regulation of Cyp4a14 in Liv-Ikk2ca mice. CYP2E1 and CYP4A are the two major CYP enzymes that generate superoxide under pathophysiological conditions [52]. SOD2 protects against mitochondrial damage by converting superoxide to the less reactive $\mathrm{H}_{2} \mathrm{O}_{2}$, and GPX1 prevents many diseases by limiting $\mathrm{H}_{2} \mathrm{O}_{2}$ accumulation. NQO1 plays a key role in antioxidative response and metabolism of many toxicants and drugs [53]. ABCG2 prevents intracellular accumulation of porphyrins and oxidative injury [54]. Additionally, activation of IKK2-NF-kB causes induction of Baat (the sole enzyme for conjugation of BAs to taurine and glycine [55]) and Mdr2 (Fig. 4b), which are essential in the protection against cholestatic liver injury [56]. By coordinated downregulation of prooxidative genes CYP2E1 and CYP4A but induction of cytoprotective genes SOD2, NQO1, GPX1,
ABCG2, BAAT, and MDR2, moderate activation of IKK2NF-kB in adult hepatocytes might exert hepatoprotective effects $[3,4]$.

The present study demonstrates that moderate activation of the IKK2-NF-kB in normal adult liver causes moderate increase of lipogenesis without overt inflammation, which is associated with induction of lipogenic transcription factors PPAR $\gamma, \mathrm{LXR} \alpha$, and LXR $\beta$ [57] (Fig. 7) as well as lipogenic Fasn, Scd1, and CD36 (Fig. 4a). Thus, moderate activation of IKK2-NF-kB alone in unstressed adult hepatocytes is sufficient to cause increase of lipogenesis but not steatohepatitis. Liv-Ikk2ca mice have higher expression of a group of LXR-target genes, including Cd36, Scd1, Cyp7a1, ApoE, and Abca1 [57]. LXR is likely activated in Liv-Ikk2ca mice via induction of LXRs (Fig. 7a) and accumulation of its ligand, oxysterols due to downregulation of Cyp7b1 (Fig. 4b), an oxysterol $7 \alpha$-hydroxylase. Activation of LXR promotes lipogenesis but exerts antiinflammatory effects [58]. Thus, activation of LXRs might contribute to the increase of lipogenesis without inflammation in Liv-Ikk2ca mice (Fig. 10).

Although non-alcoholic fatty liver disease (NAFLD) is highly prevalent in modern societies, only $10-25 \%$ of NAFLD cases develop hepatic fibrosis leading to cirrhosis, end-stage liver disease or hepatocellular carcinoma [59]. NF- $\mathrm{kB}$ is activated by diverse stresses $[3,4]$, and activation 
of NF-kB plays an important role in the etiology of steatohepatitis [59]. However, activation of NF-kB also protects liver against injuries induced by inflammation and xenobiotics $[3,4]$, and hepatocyte-specific activation of NF- $\mathrm{kB}$ does not aggravate chemical hepatocarcinogenesis in transgenic mice [60]. The present study demonstrates that moderate activation of IKK2-NF-kB in unstressed adult liver produces a cytoprotective gene expression profile and increases lipogenesis without induction of gluconeogenic genes or signs of inflammation and fibrosis. It is noteworthy that liver fibrosis only occurs in the mice with neonatal activation of Ikk2 and extensive inflammation [5], but not in the Ikk2ca transgenic mice with only mild inflammation [6]. Therefore, in future studies, it is very important to identify the key factor(s) that interacts with IKK2-NF-kB during pathological conditions and switches the function of IKK2-NF-kB from liver protection to pro-inflammation and pro-fibrosis, which might allow us to selectively modulate the IKK-NF-kB pathways to improve the efficacy and decrease the toxicity of drug treatment of metabolic syndrome, infectious/inflammatory diseases, and liver diseases.

\section{Conclusions}

The present study demonstrates that moderate activation of IKK2-NF-kB in unstressed adult mouse liver produces a cytoprotective gene expression profile and increases lipogenesis without apparent signs of inflammation or fibrosis, likely due to strong activation of the anti-inflammatory IKK1-RelB alternative NF-kB pathway as well as activation of the Lxr.

\section{Additional files}

Additional file 1: List of primers used for ChIP-qPCR determination of DNA-binding of p50 in Liv-lkk2ca mice. Description of data: sequence of ChIP-qPCR primers. (XLS $21 \mathrm{~kb}$ )

Additional file 2: Hepatic mRNA expression of major bile acid transporters in adult male mice with hepatocyte-specific activation of Ikk2 (Liv-lkk2ca). Description of data: mRNA expression. (PDF 14 kb)

Additional file 3: Hepatic mRNA expression of major drug metabolizing enzymes in adult male mice with hepatocyte-specific activation of Ikk2 (Liv-lkk2ca). Description of data: mRNA expression. (PDF $20 \mathrm{~kb}$ )

\section{Abbreviations}

IKK2ca: Constitutive active IKK2; Liv-IKk2ca: Adult hepatocyte-specific activation of Ikk2; IKK1: Inhibitor of nuclear factor-kappaB (IkappaB) kinase 1; IKBa: Inhibitor of kB a; TNFa: Tumor necrosis factor a; IL-6: Interleukin-6; Pepck: Phospho-enolpyruvate carboxykinase; G6pc: Glucose-6-phosphatase, catalytic subunit; IACUC: Institutional Animal Care and Use Committee; Gapdh: Glyceraldehyde 3-phosphate dehydrogenase; Nqo1: NAD(P)H quinone oxidoreductase 1; TG: Triglycerides; CHO: Cholesterol; Saa1: Serum amyloid a1; Icam1: Intercellular adhesion molecule 1; NIK: NF-kB inducing kinase; Len2: Lipocalin-2; Ccl2: (C-C motif) ligand 2; Nos2: NO synthase 2; Tgfß: Transforming growth factor $\beta$; $a-S m a: ~ a-s m o o t h$ muscle actin; Col1a1: Collagen 1a1; Sod2: Superoxide dismutase 2; Gpx1: Glutathione peroxidase 1; Cat: Catalase; Ho-1: Heme oxygenase-1; Ephx1: Epoxide hydrolase 1; Gclc: Glutamate-cysteine ligase catalytic subunit; BAs: Bile acids; Gck: Glucokinase; Gys2: Glycogen synthase 2; Fasn: Fatty acid
}

synthase; Lpl: Lipoprotein lipase; Scd1: Stearoyl-CoA desaturase 1; ApoE: Apolipoprotein E; Acox1: Acyl-CoA oxidase 1; Cyp4a14: Cytochrome P450 4a14; Baat: Bile acid; CoA: Amino acid N-acyltransferase; TauT: Taurine transporter: Oatp1a1: Organic anion-transporting polypeptide 1a1; Mdr2: Multi-drug resistance 2; DPGs: Drug-processing genes; Por: P450 oxidoreductase; Ugts: UDP-glucuronosyltransferases; Sults: Sulfotransferases; Ugp2: UDP-glucose pyrophosphorylase 2; Papss2: 3'-phosphoadenosine 5'-phosphosulfate synthetase 2; Gsts: Glutathione S-transferases; HNF1a: Hepatocyte nuclear factor 1a; FXR: Farnesoid X receptor; LXRa: Liver X receptor a; PPARY: Peroxisome proliferator-activated receptor $\gamma$; PGC1a: PPAR $y$ coactivator 1a; SHP: Small heterodimer partner; AhR: Aryl hydrocarbon receptor; CAR: Constitutive active receptor; PXR: Pregnane X receptor; NRF2: Nuclear factor (erythroid-derived 2)-like 2; RXRa: Retinoid X receptor a; GR: Glucocorticoid receptor; NAFLD: Non-alcoholic fatty liver disease.

\section{Competing interests}

The authors declare that they have no competing interests.

\section{Authors' contributions}

$\mathrm{HL}$ designed the study; $\mathrm{HL}$ coordinated the study; $\mathrm{HL}, \mathrm{XL}$, and QZ performed the study; HL, XL, and QZ analyzed the data; XL and QZ helped to draft the manuscript; and $\mathrm{HL}$ wrote the manuscript. All authors read and approved the final manuscript.

\section{Acknowledgements}

We thank Lesley Baker and Shangdong Guo in Dr. Lu's laboratory for critical review of this manuscript. This research was supported by National Institutes of Health (NIH) grant ES019487 (http://grants.nih.gov/grants/guide/). The funders had no role in study design, data collection and analysis, decision to publish, or preparation of the manuscript.

Received: 29 December 2014 Accepted: 21 July 2015

Published online: 30 July 2015

\section{References}

1. Hayden MS, Ghosh S. NF-kappaB, the first quarter-century: remarkable progress and outstanding questions. Genes Dev. 2012;26(3):203-34.

2. Liu F, Xia Y, Parker AS, Verma IM. IKK biology. Immunol Rev. 2012;246(1):239-53.

3. Sun B, Karin M. NF-kappaB signaling, liver disease and hepatoprotective agents. Oncogene. 2008;27(48):6228-44.

4. Luedde T, Schwabe RF. NF-kappaB in the liver-linking injury, fibrosis and hepatocellular carcinoma. Nat Rev Gastroenterol Hepatol. 2011;8(2):108-18.

5. Sunami Y, Leithauser F, Gul S, Fiedler K, Guldiken N, Espenlaub S, et al. Hepatic activation of IKK/NFkappaB signaling induces liver fibrosis via macrophage-mediated chronic inflammation. Hepatology. 2012;56(3):1117-28.

6. Cai D, Yuan M, Frantz DF, Melendez PA, Hansen L, Lee J, et al. Local and systemic insulin resistance resulting from hepatic activation of IKK-beta and NF-kappaB. Nat Med. 2005;11(2):183-90.

7. Karin M, Yamamoto Y, Wang QM. The IKK NF-kappa B system: a treasure trove for drug development. Nat Rev Drug Discov. 2004;3(1):17-26.

8. Tujios S, Fontana RJ. Mechanisms of drug-induced liver injury: from bedside to bench. Nat Rev Gastroenterol Hepatol. 2011;8(4):202-11.

9. Sasaki Y, Derudder E, Hobeika E, Pelanda R, Reth M, Rajewsky K, et al. Canonical NF-kappaB activity, dispensable for B cell development, replaces BAFF-receptor signals and promotes B cell proliferation upon activation. Immunity. 2006;24(6):729-39.

10. Zhang Q, Lei X, Lu H. Alterations of epigenetic signatures in hepatocyte nuclear factor $4 a$ alpha deficient mouse liver determined by improved ChIP-qPCR and (h)MeDIP-qPCR assays. PLoS One. 2014;9(1), e84925.

11. Hollander PM, Ernster L. Studies on the reaction mechanism of DT diaphorase. Action of dead-end inhibitors and effects of phospholipids. Arch Biochem Biophys. 1975;169(2):560-7.

12. Lu H, Cui W, Klaassen CD. Nrf2 protects against 2,3,7,8-tetrachlorodibenzo-p-dioxin (TCDD)-induced oxidative injury and steatohepatitis. Toxicol Appl Pharmacol. 2011;256(2):122-35.

13. Ellman GL. Tissue sulfhydryl groups. Arch Biochem Biophys. 1959:82(1):70-7.

14. Yoshimi A, Goyama S, Watanabe-Okochi N, Yoshiki Y, Nannya Y, Nitta E, et al. Evi1 represses PTEN expression and activates PI3K/AKT/mTOR via interactions with polycomb proteins. Blood. 2011;117(13):3617-28. 
15. da Silva CM, Spinelli E, Rodrigues SV. Fast and sensitive collagen quantification by alkaline hydrolysis/hydroxyproline assay. Food Chem. 2015;173:619-23.

16. Ling L, Cao Z, Goeddel DV. NF-kappaB-inducing kinase activates IKK-alpha by phosphorylation of Ser-176. Proc Natl Acad Sci U S A. 1998;95(7):3792-7.

17. Srinivasan G, Aitken JD, Zhang B, Carvalho FA, Chassaing B, Shashidharamurthy $\mathrm{R}$, et al. Lipocalin 2 deficiency dysregulates iron homeostasis and exacerbates endotoxin-induced sepsis. J Immunol. 2012;189(4):1911-9.

18. Guo H, Jin D, Zhang Y, Wright W, Bazuine M, Brockman DA, et al. Lipocalin-2 deficiency impairs thermogenesis and potentiates diet-induced insulin resistance in mice. Diabetes. 2010;59(6):1376-85.

19. Ma A, Malynn BA. A20: linking a complex regulator of ubiquitylation to immunity and human disease. Nat Rev Immunol. 2012;12(11):774-85.

20. Yamaguchi N, Oyama M, Kozuka-Hata H, Inoue J. Involvement of A20 in the molecular switch that activates the non-canonical NF-small ka, CyrillicB pathway. Sci Rep. 2013;3:2568.

21. Zordoky BN, El-Kadi AO. Role of NF-kappaB in the regulation of cytochrome p450 enzymes. Curr Drug Metab. 2009;10(2):164-78.

22. Peng L, Yoo B, Gunewardena SS, Lu H, Klaassen CD, Zhong XB. RNA sequencing reveals dynamic changes of mRNA abundance of cytochromes P450 and their alternative transcripts during mouse liver development. Drug Metab Dispos. 2012;40(6):1198-209.

23. Lu H, Gunewardena S, Cui JY, Yoo B, Zhong XB, Klaassen CD. RNA-sequencing quantification of hepatic ontogeny and tissue distribution of mRNAs of phase II enzymes in mice. Drug Metab Dispos. 2013;41(4):844-57.

24. Schrem H, Klempnauer J, Borlak J. Liver-enriched transcription factors in liver function and development. Part II: the C/EBPS and D site-binding protein in cell cycle control, carcinogenesis, circadian gene regulation, liver regeneration, apoptosis, and liver-specific gene regulation. Pharmacol Rev. 2004;56(2):291-330.

25. Schrem H, Klempnauer J, Borlak J. Liver-enriched transcription factors in liver function and development. Part I: the hepatocyte nuclear factor network and liver-specific gene expression. Pharmacol Rev. 2002;54(1):129-58.

26. Klaassen CD, Slitt AL. Regulation of hepatic transporters by xenobiotic receptors. Curr Drug Metab. 2005;6(4):309-28.

27. Zhang W, Patil S, Chauhan B, Guo S, Powell DR, Le J, et al. FoxO1 regulates multiple metabolic pathways in the liver: effects on gluconeogenic, glycolytic, and lipogenic gene expression. J Biol Chem. 2006;281(15):10105-17.

28. Miao H, Zhang Y, Lu Z, Liu Q, Gan L. FOXO1 involvement in insulin resistance-related pro-inflammatory cytokine production in hepatocytes. Inflamm Res. 2012;61(4):349-58.

29. Luedde T, Heinrichsdorff J, de Lorenzi R, De Vos R, Roskams T, Pasparakis M. IKK1 and IKK2 cooperate to maintain bile duct integrity in the liver. Proc Natl Acad Sci U S A. 2008;105(28):9733-8.

30. Dong J, Jimi E, Zeiss C, Hayden MS, Ghosh S. Constitutively active NF-kappaB triggers systemic TNFalpha-dependent inflammation and localized TNFalpha-independent inflammatory disease. Genes Dev. 2010;24(16):1709-17

31. Gasparini C, Foxwell BM, Feldmann M. RelB/p50 regulates TNF production in LPS-stimulated dendritic cells and macrophages. Cytokine. 2013;61(3):736-40.

32. Weih F, Carrasco D, Durham SK, Barton DS, Rizzo CA, Ryseck RP, et al. Multiorgan inflammation and hematopoietic abnormalities in mice with a targeted disruption of RelB, a member of the NF-kappa B/Rel family. Cell. 1995;80(2):331-40.

33. Weih F, Durham SK, Barton DS, Sha WC, Baltimore D, Bravo R. p50-NF-kappaB complexes partially compensate for the absence of RelB: severely increased pathology in p50(-/-)relB(-/-) double-knockout mice. J Exp Med. 1997;185(7):1359-70.

34. Chen X, El Gazzar M, Yoza BK, McCall CE. The NF-kappaB factor RelB and histone $\mathrm{H} 3$ lysine methyltransferase $\mathrm{G} 9$ a directly interact to generate epigenetic silencing in endotoxin tolerance. J Biol Chem. 2009;284:27857-65.

35. Lawrence T, Bebien M, Liu GY, Nizet V, Karin M. IKKalpha limits macrophage NF-kappaB activation and contributes to the resolution of inflammation. Nature. 2005:434(7037):1138-43.

36. O'Mahony A, Lin X, Geleziunas R, Greene WC. Activation of the heterodimeric IkappaB kinase alpha (IKKalpha)-IKKbeta complex is directional: IKKalpha regulates IKKbeta under both basal and stimulated conditions. Mol Cell Biol. 2000;20(4):1170-8.

37. Papa S, Bubici C, Zazzeroni F, Franzoso G. Mechanisms of liver disease: cross-talk between the NF-kappaB and JNK pathways. Biol Chem. 2009;390(10):965-76.
38. Henkel T, Zabel U, van Zee K, Muller JM, Fanning E, Baeuerle PA Intramolecular masking of the nuclear location signal and dimerization domain in the precursor for the p50 NF-kappa B subunit. Cell. 1992;68(6):1121-33.

39. Miao H, Zhang Y, Lu Z, Yu L, Gan L. FOXO1 increases CCL20 to promote NF-kappaB-dependent lymphocyte chemotaxis. Mol Endocrinol. 2012;26(3):423-37.

40. Su D, Coudriet GM, Hyun Kim D, Lu Y, Perdomo G, Qu S, et al. FoxO1 links insulin resistance to proinflammatory cytokine IL-1beta production in macrophages. Diabetes. 2009;58(11):2624-33.

41. Ito $Y$, Daitoku H, Fukamizu A. Foxo1 increases pro-inflammatory gene expression by inducing C/EBPbeta in TNF-alpha-treated adipocytes. Biochem Biophys Res Commun. 2009;378(2):290-5.

42. Sekine K, Chen YR, Kojima N, Ogata K, Fukamizu A, Miyajima A. Foxo1 links insulin signaling to C/EBPalpha and regulates gluconeogenesis during liver development. EMBO J. 2007;26(15):3607-15.

43. Tikhanovich I, Cox J, Weinman SA. Forkhead box class $O$ transcription factors in liver function and disease. J Gastroenterol Hepatol. 2013;28 Suppl $1: 125-31$.

44. Lee DF, Kuo HP, Chen CT, Hsu JM, Chou CK, Wei Y, et al. IKK beta suppression of TSC1 links inflammation and tumor angiogenesis via the mTOR pathway. Cell. 2007;130(3):440-55.

45. Saemann MD, Haidinger M, Hecking M, Horl WH, Weichhart T. The multifunctional role of mTOR in innate immunity: implications for transplant immunity. Am J Transplant. 2009;9(12):2655-61.

46. Assenat E, Gerbal-chaloin S, Maurel P, Vilarem MJ, Pascussi JM. Is nuclear factor kappa-B the missing link between inflammation, cancer and alteration in hepatic drug metabolism in patients with cancer? Eur J Cancer. 2006;42(6):785-92.

47. Plant NJ, Gibson GG. Evaluation of the toxicological relevance of CYP3A4 induction. Curr Opin Drug Discov Devel. 2003;6(1):50-6.

48. Nikolaidou-Neokosmidou V, Zannis VI, Kardassis D. Inhibition of hepatocyte nuclear factor 4 transcriptional activity by the nuclear factor kappaB pathway. Biochem J. 2006;398(3):439-50.

49. Morgan MJ, Liu ZG. Crosstalk of reactive oxygen species and NF-kappaB signaling. Cell Res. 2011;21(1):103-15.

50. Josson S, Xu Y, Fang F, Dhar SK, St Clair DK, St Clair WH. RelB regulates manganese superoxide dismutase gene and resistance to ionizing radiation of prostate cancer cells. Oncogene. 2006;25(10):1554-9.

51. Pradhan M, Bembinster LA, Baumgarten SC, Frasor J. Proinflammatory cytokines enhance estrogen-dependent expression of the multidrug transporter gene ABCG2 through estrogen receptor and NF\{kappa\}B cooperativity at adjacent response elements. J Biol Chem. 2010;285(41):31100-6.

52. Hardwick JP, Osei-Hyiaman D, Wiland H, Abdelmegeed MA, Song BJ. PPAR/ RXR regulation of fatty acid metabolism and fatty acid omega-hydroxylase (CYP4) isozymes: Implications for prevention of lipotoxicity in fatty liver disease. PPAR Res. 2009;2009:952734.

53. Dinkova-Kostova AT, Talalay P. NAD(P)H:quinone acceptor oxidoreductase 1 (NQO1), a multifunctional antioxidant enzyme and exceptionally versatile cytoprotector. Arch Biochem Biophys. 2010;501(1):116-23.

54. Krishnamurthy $P$, Schuetz JD. The role of ABCG2 and ABCB6 in porphyrin metabolism and cell survival. Curr Pharm Biotechnol. 2011;12(4):647-55.

55. Falany CN, Johnson MR, Barnes S, Diasio RB. Glycine and taurine conjugation of bile acids by a single enzyme. Molecular cloning and expression of human liver bile acid CoA:amino acid N-acyltransferase. J Biol Chem. 1994;269(30):19375-9.

56. Jungst C, Lammert F. Cholestatic liver disease. Dig Dis. 2013;31(1):152-4.

57. Ducheix S, Montagner A, Theodorou V, Ferrier L, Guillou H. The liver X receptor: a master regulator of the gut-liver axis and a target for non alcoholic fatty liver disease. Biochem Pharmacol. 2013;86(1):96-105.

58. Liu Y, de Qiu K, Ma X. Liver X receptors bridge hepatic lipid metabolism and inflammation. J Dig Dis. 2012;13(2):69-74.

59. Farrell GC, van Rooyen D, Gan L, Chitturi S. NASH is an inflammatory disorder: pathogenic, prognostic and therapeutic implications. Gut Liver. 2012;6(2):149-71.

60. Murray S, Briasoulis E, Linardou H, Bafaloukos D, Papadimitriou C. Taxane resistance in breast cancer: mechanisms, predictive biomarkers and circumvention strategies. Cancer Treat Rev. 2012;38(7):890-903. 